\title{
INFLUENCE OF SHIELding GaS MiXTURE TyPe ON UlTiMATE TENSILE STRENGTH OF LASER-WELDED JOINTS IN DUPLEX STAINLESS STEEL 2205
}

\author{
Angela Topić \& Nikola Knezović
}
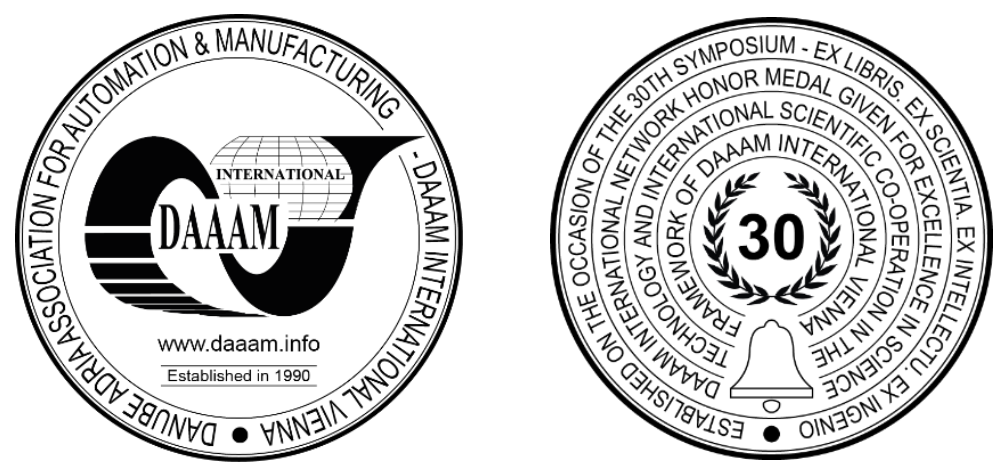

This Publication has to be referred as: Topic, A[ngela] \& Knezovic, N[ikola] (2020). Influence of Shielding Gas Mixture Type on Ultimate Tensile Strength of Laser-Welded Joints in Duplex Stainless Steel 2205, Proceedings of the 31st DAAAM International Symposium, pp.0408-0411, B. Katalinic (Ed.), Published by DAAAM International, ISBN 978-3-902734-29-7, ISSN 1726-9679, Vienna, Austria

DOI: $10.2507 / 31$ st.daaam.proceedings.056

\begin{abstract}
During the laser welding of duplex stainless steel, shielding gases are inevitable. Their main goal is the protection of the molten metal and heat-affected zone from the effect of the surrounding atmosphere, but they also have other tasks to fulfil in order to obtain the best possible quality of the welded joint. Usually, the gases which are used are argon, nitrogen, helium and their mixtures. The experiment was carried out according to the experimental model with these gases and their mixtures. Base material was duplex stainless steel 2205 (W. Nr. 1.4462). The analysis revealed that the impact of the shielding gas mixtures on the ultimate tensile strength was not significant since all the specimens have shown similar results. However, it is important to emphasize that all specimens have high ultimate tensile strength (comparing with the requirements of appropriate standards). It is probably due to excessive ferrite content in the weld metal and it should not be a problem by itself, but it could be an indication of poor impact toughness. Considering that, toughness testing is the suggestion for future experiments and researches.
\end{abstract}

Keywords: Duplex stainless steel; Welding; Shielding gas; Ultimate tensile strength.

\section{Introduction}

Stainless steels are the group of steels known mostly for their great corrosion resistance. They can be martensitic, ferritic, austenitic or duplex (austenitic/ferritic), depending on their microstructure [1]. Because of their mixed microstructure, duplex stainless steels are the most interesting for research amongst these. The combined lattice arrangement of ferrite and austenite gives greater strength and offers excellent resistance against Stress Corrosion Cracking (SCC) [2]. These steels solidify as ferrite which partially transforms to austenite during the cooling process. Duplex stainless steels are mostly divided into five classes, according to their corrosion resistance and chemical composition, and they are ranged from lower alloyed grades (lean) to highly alloyed grades (hyper duplex). Currently, the most used duplex steels are these with around $22 \%$ of chromium and $3 \%$ of molybdenum. One of these steels is grade AISI (American Iron and Steel Institute) 2205 (W. Nr. 1.4462), which is used in this experiment [3]. 
Generally, good properties are possible to achieve when austenite and ferrite both are ranging from $30 \%$ to $70 \%$, including both welded metal and HAZ (Heat Affected Zone). However, approximately equal amounts of both phases should be obtained. If it is not the case, then austenite is favoured since it provides better toughness. The chemical composition of base material and additional material, shielding gas composition and the cooling rate during the process are the key factors which affect the final microstructure [4]. Welding of duplex stainless steels is a difficult process and one of the major drawbacks in their use, mostly due to a great amount of alloying elements and a lot of heating/cooling cycles, which contributes to the formation of harmful and undesirable intermetallic phases, especially in higher alloyed grades [5].

\section{Problems and current situation}

Laser welding has a great advantage compared with other welding processes since it increases the production rate, but for duplex stainless steels, there are some negative consequences. For example, ferrite formation is increased due to high cooling rates. In other processes, it could be balanced by the use of additional material (welding wire) with alloying elements which promote the formation of austenite, but laser welding is usually done without additional material, which means that is not the convenient solution in this case. However, since a larger amount of ferrite deteriorates toughness properties and corrosion resistance, something should be done to avoid that [6].

An interesting approach is to affect the microstructure of a welded joint with shielding gas. The shielding gases have a significant role in welding processes. They protect the molten metal and HAZ (Heat Affected Zone) from the environmental atmosphere. They protect the molten pool and heat-affected zone from the effect of the surrounding atmosphere, alter the microstructure, affect the weld geometry and protect the welding equipment from the spatter. Argon, helium and nitrogen (or their combinations) are usually used in laser welding. Acceptable geometry could be obtained with all gases [7]. While argon and helium are inert gases (they do not affect metallurgy of welded joint), nitrogen is reactive and it promotes austenite formation, which means it could compensate ferritization which usually occurs [8]. However, an excessive amount of nitrogen tends to decrease some mechanical properties and cause electric arc instability, so it has to be kept in a certain range [9].

Since researches [6] and [10] proved that mixtures containing two of gases mentioned (or all three of them) provide satisfying and acceptable geometry, appearance and quality of the welds, the motive for this experiment was to test the ultimate tensile strength of specimens produced with laser welding and with different combinations of shielding gases.

\section{Experimental work}

To conduct the experiment, the plan has to be made first. There were three different gases included and the plan was to test as many combinations as possible, but it would be excessively time-consuming to try many mixtures. It was decided to test the minimum necessary combinations, which is seven. Also, for every combination there were four specimens, to obtain more precise results (to eliminate the possibility for the statistical mistake). A detailed explanation of mixtures used and specimens labelling is given in Table 1.

\begin{tabular}{|c|c|c|c|c|}
\hline \multirow{2}{*}{ Mixture type } & \multirow{2}{*}{ Specimens } & \multicolumn{3}{|c|}{ Mixture components (\%) } \\
\cline { 3 - 5 } & & Argon & Nitrogen & Helium \\
\hline I & $1-4$ & 100 & 0 & 0 \\
\hline II & $5-8$ & 0 & 100 & 0 \\
\hline III & $9-12$ & 0 & 0 & 100 \\
\hline IV & $13-16$ & 50 & 50 & 0 \\
\hline V & $17-20$ & 0 & 50 & 50 \\
\hline VI & $21-24$ & 50 & 0 & 50 \\
\hline VII & $25-28$ & 33,33 & 33,33 & 33,33 \\
\hline
\end{tabular}

Table 1. Specimens and shielding gas mixture types

It is important to mention some limitations for this experiment. First of all, this is a minimum of mixtures combinations which are necessary to have some results (or indicators, at least). Of course, more combinations would give more reliable results, but at this point, it was too expensive and too complex to produce additional mixtures. However, results obtained in this research would be valuable guidelines for the future (for example, it will be clearer which combinations should be tested next). Also, some other gases except these three can also be used. Argon is cheap and easily acquirable, nitrogen decreases ferritization and helium tends to accelerate the welding process and that is the reason why these three gases are most popular amongst all. However, some other gases could also be used, but the most convenient option for this research was to try these options.

The welding was done with "ROFIN CW 020" laser (Nd:YAG type), which have continuous power of $2 \mathrm{~kW}$. The beam was transferred using optical fibre with a $600-\mu \mathrm{m}$ core diameter. Beam diameter in the focus was $0,6 \mathrm{~mm}$. Focusing optics were controlled and moved using robotic hand "IGM Limat RT 280", with 6 axes of movement. 
Other constant parameters were: power $(1800 \mathrm{~W})$, focal length $(120 \mathrm{~mm})$, gas nozzle tip diameter $(5 \mathrm{~mm})$ and distance of gas nozzle tip from the workpiece $(8 \mathrm{~mm})$. Base material was 2205 duplex stainless steel plates $(250 \times 130 \times 2 \mathrm{~mm})$. All plates were machined, cleaned and degreased using $96 \%$ ethanol solution prior to the welding. Specimens for ultimate tensile strength testing were cut from welded samples (the position of the weld is shown in Fig. 1).

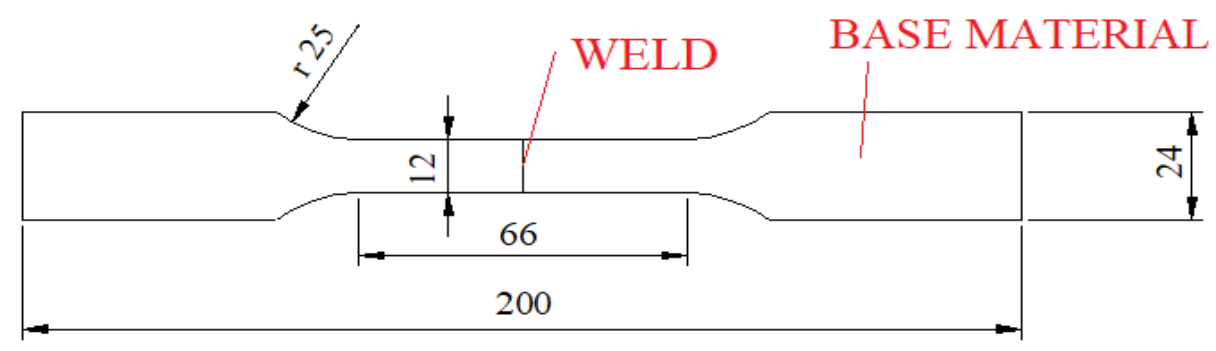

All dimensions are in milimeters

Fig. 1. Specimen for the ultimate tensile strength testing

Obtained results were then compared with the requirements of standard EN 10088-2:2014, which defines minimum requirements for mechanical properties and technical delivery conditions for sheet/plate and strip of corrosion resisting steels for general purposes.

\section{Results, conclusion and suggestions for future researches}

To obtain reliable results of the ultimate tensile strength testing, it should be managed to have as much as possible specimens fractured at the welded joint. For all seven mixture types, only last one (specimens 25-28) has only one specimen fractured at the welded joint. All other types have at least two specimens fractured at the welded joint (some mixture types have three and some all four specimens). Other specimens were fractured at the base material. Since HAZ (Heat Affected Zone) is quite narrow in the laser welding process, that results should not be taken as reliable (welding process probably did not induce significant changes in microstructure). Table 2 shows the results of ultimate tensile strength $\left(\mathrm{R}_{\mathrm{m}}\right)$ testing for all 28 specimens (specimens with a fracture in the base material are marked with *).

\begin{tabular}{|c|c|}
\hline Specimen & $\left.\mathbf{R}_{\mathbf{m}} \mathbf{( \mathbf { N }} / \mathbf{m m}^{\mathbf{2}}\right)$ \\
\hline 1 & 808,73 \\
\hline 2 & 809,35 \\
\hline 3 & 822,83 \\
\hline 4 & 821,02 \\
\hline 5 & 825,25 \\
\hline 6 & $816,78^{*}$ \\
\hline 7 & 832,50 \\
\hline 8 & 836,73 \\
\hline 9 & 830,08 \\
\hline 10 & 840,37 \\
\hline 11 & 819,80 \\
\hline 12 & $832,50^{*}$ \\
\hline 13 & $816,78^{*}$ \\
\hline 14 & $839,10^{*}$ \\
\hline
\end{tabular}

\begin{tabular}{|c|c|}
\hline Specimen & $\mathbf{R}_{\mathbf{m}}\left(\mathbf{N} / \mathbf{m m}^{\mathbf{2}}\right)$ \\
\hline 15 & 828,22 \\
\hline 16 & $831,83^{*}$ \\
\hline 17 & 828,82 \\
\hline 18 & $834,87^{*}$ \\
\hline 19 & 828,22 \\
\hline 20 & $819,13^{*}$ \\
\hline 21 & 816,12 \\
\hline 22 & 830,03 \\
\hline 23 & $814,90^{*}$ \\
\hline 24 & $814,90^{*}$ \\
\hline 25 & $820,35^{*}$ \\
\hline 26 & $833,05^{*}$ \\
\hline 27 & 813,08 \\
\hline 28 & $837,28^{*}$ \\
\hline
\end{tabular}

Table 2. Results of ultimate tensile strength testing

Fig. 2. shows specimens with a fracture in a welded joint (a) and in the base material (b). Fractures in base material probably occur due to smooth and clean surface of grip sections, which caused unequal force transfer.

Standard EN 10088-2:2014 defines requirements for ultimate tensile strength for this duplex stainless steel grade. The range is from $640 \mathrm{~N} / \mathrm{mm}^{2}$ to $840 \mathrm{~N} / \mathrm{mm}^{2}$. It can be seen in Table 2 that all of the specimens are close to the maximum value defined by the standard (specimen 10 even exceeds it) and that could be interpreted as a positive outcome. However, ultimate tensile strength tends to increase with more ferrite amount in duplex stainless steel (that is the reason why there is a maximum allowed value in appropriate standards). With larger ferrite amount, impact toughness and corrosion resistance (especially pitting corrosion resistance) tend to decrease. In terms of the common use of this duplex stainless steel, low impact toughness and poor corrosion resistance are more important factors than the great ultimate tensile strength. 


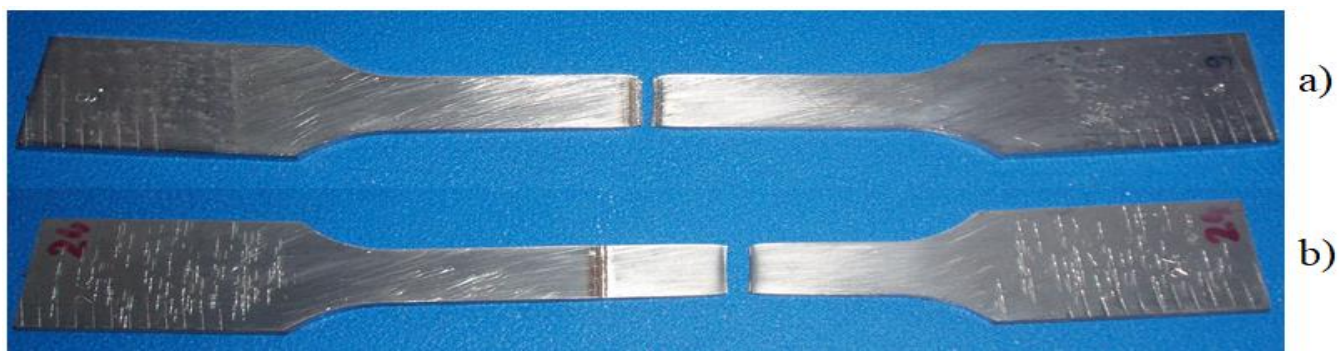

Fig. 2. Specimens with a fracture in a welded joint (a) and in the base material (b)

Shielding gas mixture type obviously does not have a significant influence on ultimate tensile strength, but it has to be mentioned that all of the mixture types used probably caused ferritization in the weld metal and an excessive amount of ferrite. Use of nitrogen in shielding gas should be researched further, but its amounts have to be defined more precisely and more strictly if any positive effects are to be found.

Further researches should include impact toughness testing and testing of pitting corrosion resistance which would give even more reliable guidelines for ferrite amount. Of course, the best idea is to measure the ferrite/austenite ratio using some modern method (X-ray diffractometry, for example), which should also be done in future.

\section{Acknowledgments}

The materials and shielding gases were sponsored by Messer Croatia Plin d.o.o. We express our thanks to the Messer Croatia Plin and ROFIN-SINAR Laser (Hamburg) for their technical and financial support.

\section{Literature}

[1] Karlsson, L. (2004). Stainless Steels: Past, Present and Future. Svetsaren, Vol. 59, No. 1, 2004, pp. 47-52., 03414248

[2] Olsson, J. \& Snis, M. (2007). Duplex - A new generation of stainless steels for desalination plants. Desalination, Vol. 205, No. 1-3, 2007, pp. 104-113., 0011-9164, https://doi.org/10.1016/j.desal.2006.02.051

[3] Karlsson, L. (2012). Welding duplex stainless steels - a review of current recommendations, Welding in the World, Vol. 56, No. 5-6, 2012, pp. 65-76., ISSN: 1878-6669, 10.1007/BF03321351

[4] Knezović, N., Topić, A., Garašić, I., Jurić, I. (2019). Application of wire and arc additive manufacturing for fabrication of duplex stainless steel product, Proceedings of 30th International DAAAM Symposium "Intelligent Manufacturing \& Automation", Zadar, ISSN: 1726-9679, ISBN: 978-3-902734-22-8, Katalinic, B. (Ed.), pp. 05990604., DAAAM International, Vienna, 10.2507/30th.daaam.proceedings.081

[5] Kang, D.H. \& Lee, H.W. (2012). Effect of Different Chromium Additions on the Microstructure and Mechanical Properties of Multipass Weld Joint of Duplex Stainless Steel. Metall Mater Trans A, Vol. 43, 2012, pp. 4678-4687., ISSN: 1073-5623, 10.1007/s11661-012-1310-6

[6] Topić, A., Bauer, B., Kožuh, Z., \& Knezović, N. (2016). Gas composition influence on the microstructure and geometry of laser-welded joints in duplex stainless steel, Proceedings of 27th International DAAAM Symposium "Intelligent Manufacturing \& Automation", Mostar, ISSN: 1726-9679, ISBN: 978-3-902734-08-2, Katalinic, B. (Ed.), pp. 734-742., DAAAM International, Vienna, 10.2507/27th.daaam.proceedings.106

[7] Faerber, M. \& Berkmann, J. (1997). Process gases for laser welding, Proceedings of Laser and Optics Manufacturing III, Munich, ISBN: 978-0-819425-17-1, H. J. F. Beckmann, L. (Ed.), pp. 656-661., SPIE, Bellingham, https://doi.org/10.1117/12.281131

[8] Bauer, B., Kralj, S. \& Miculinić, M. (2007). Laser welding of duplex stainless steel with different shielding gases. Weld world., Vol. 51, 2007, pp. 835-842., ISSN: 0043-2288, https://www.bib.irb.hr/370566

[9] Zhang, Z., Jing, H., Xu, L., Han, Y., Zhao, L. \& Zhou C. (2017). Effects of nitrogen in shielding gas on microstructure evolution and localized corrosion behavior of duplex stainless steel welding joint. Appl Surf Sci, Vol. 404, 2017, pp. 110-128., ISSN: 0169-4332, http://dx.doi.org/10.1016/j.apsusc.2017.01.252

[10] Marquardt, E., \& Sitte, G. (1996). Plasma-und Laserstrahlschweißen von Feinblechen aus Duplexstahl 1.4462. Abschlußbericht, SLV Halle 